\title{
Feasibility of virtual 3-Fr percutaneous coronary intervention using standard guiding catheters
}

\author{
Tsuyoshi Honda ${ }^{1}$, Kazuteru Fujimoto², Yuji Miyao \\ ${ }^{1}$ Department of Cardiology, National Hospital Organisation, Kumamoto Saisyunsou Hospital, Kumamoto, Japan \\ ${ }^{2}$ Department of Cardiology, Cardiovascular Centre, National Hospital Organisation, Kumamoto Medical Centre, Kumamoto, Japan
}

Postep Kardiol Inter 2014; 10, 4 (38): 231-237

DOI: $10.5114 /$ pwki.2014.46763

\begin{abstract}
A bstract
Introduction: Recent studies have reported the efficacy of sheathless percutaneous coronary intervention (PCI) using hydrophilic-coated 5-Fr guiding catheters that are one to two $\mathrm{Fr}$ sizes smaller in diameter than the corresponding introducer sheath (virtual 3-Fr PCl). However, the limited number of shapes of hydrophilic-coated guiding catheters occasionally makes them difficult to engage and control.

Aim: To evaluate the efficacy and feasibility of virtual 3-Fr PCl using standard guiding catheters of various shapes.

Material and methods: We identified 35 consecutive patients with stable angina, who underwent virtual 3-Fr PCl using either hydrophilic-coated guiding catheters (Works ${ }^{\mathrm{TM}}$, Medikit, Japan) or standard guiding catheters (Heartrail ${ }^{\mathrm{TM}}$, Terumo, Japan).

Results: Thirty-five patients were identified (63\% men; mean age $70 \pm 13$ years). In 2 cases, hydrophilic-coated guiding catheters were exchanged to standard guiding catheters because of difficulty in engaging the target coronary arteries. Ultimately, standard guiding catheters were used in 20 patients (57\%) and hydrophilic-coated catheters were used in 15 (43\%). One of 20 patients treated with standard guiding catheters and 1 of 15 treated with hydrophilic-coated guiding catheters underwent the 4-in-3 "slender mother and child" PCl technique due to difficulty of stent deployment. There were no differences between the two groups in $\mathrm{PCl}$ procedural variables such as procedural time, fluoroscopy time, radiation dose, or contrast dye volume. There were no access site-related complications in this study.

Conclusions: These findings indicate that virtual 3-Fr PCl using standard guiding catheters is as efficient and safe as virtual 3- $\mathrm{Fr}$ $\mathrm{PCl}$ using hydrophilic-coated guiding catheters.
\end{abstract}

Key words: virtual 3-Fr percutaneous coronary intervention.

\section{Introduction}

Since Grüntzig introduced percutaneous coronary intervention $(\mathrm{PCl})$, downsizing of $\mathrm{PCl}$ devices has allowed $\mathrm{PCl}$ to be performed with a 6-Fr or even smaller system, and this size reduction has been associated with lower access site complications [1-4]. Recent studies have reported the use of a novel PCI system that employs a hydrophilic-coated sheathless guiding catheter (virtual 3-Fr, Medikit, Japan) with an outer diameter of 0.067 inches $(1.70 \mathrm{~mm})$ and inner diameter of 0.059 inches $(1.50 \mathrm{~mm})$ [5-7]. Because of its unique sheathless configuration, its outer diameter is similar to that of a conventional 3-Fr introducer sheath, with an inner diameter close in size to a conventional 5-Fr guiding catheter. These features allow this sheathless system to be used as the sole guiding catheter, while arterial damage at the puncture site remains equivalent to that caused by a 3-Fr introducer sheath. A previous study showed the feasibility of $\mathrm{PCl}$ with this virtual 3-Fr system using a hydrophilic-coated sheathless guiding catheter (Works ${ }^{\mathrm{TM}}$, Medikit, Japan) for the treatment of a variety of coronary artery lesions [6]. However, it is uncertain if virtual 3-Fr PCl using a standard guiding catheter (Heartrail ${ }^{\mathrm{TM}}$, Terumo, Japan) is feasible and safe.

\section{Aim}

Therefore, the purpose of this study was to examine the feasibility of virtual $3-\mathrm{Fr} \mathrm{PCl}$ using a standard guiding catheter.

\section{Material and methods}

Study population

We retrospectively analysed 35 consecutive patients who underwent virtual $3-\mathrm{Fr} \mathrm{PCl}$ in Kumamoto Medical

\section{Corresponding author:}

Tsuyoshi Honda MD, PhD, Department of Cardiology, National Hospital Organization, Kumamoto Saisyunsou Hospital, 2659 Suya, Koushi City, Kumamoto 861-1196, Japan, phone/fax: +8196242 1000/+8196242 2619, e-mail: tsuyohonda-circ@umin.ac.jp

Received: 4.08.2014, accepted: 25.08.2014. 
Centre for coronary artery lesions. Virtual 3- $\mathrm{Fr} \mathrm{PCl}$ was excluded from interventions requiring the use of angioplasty devices that were not compatible, such as a rotablator (Boston Scientific, USA) or cutting balloons (Boston Scientific, USA). Patients with left main trunk lesions and/or cardiogenic shock were also excluded. Patients with acute myocardial infarction were excluded because these patients often require aspiration devices that are not compatible with this 3-Fr sheathless system. All procedures were performed by a single physician (Honda T.). The shapes of the guiding catheters were chosen by the physician according to the angiographic findings.

\section{Analysis of coronary risk factors for coronary artery disease}

The following traditional coronary artery disease risk factors were used for statistical analysis: hypertension (HT), dyslipidaemia (DL), diabetes mellitus (DM), current cigarette smoking habit, and body mass index (BMI). The HT was defined as blood pressure $\geq 140 / 90 \mathrm{~mm} \mathrm{Hg}$ and/ or the use of antihypertensive medication. The DL was defined as high-density lipoprotein-cholesterol (HDL-C) $<40 \mathrm{mg} / \mathrm{dl}$ and/or low-density lipoprotein-cholesterol $(\mathrm{LDL}-\mathrm{C})>140 \mathrm{mg} / \mathrm{dl}$ and/or triglycerides $(\mathrm{TG})>150 \mathrm{mg} / \mathrm{dl}$ and/or the use of antidyslipidaemic medication. The DM was defined as a fasting blood glucose $\geq 126 \mathrm{mg} / \mathrm{dl}$ and/ or haemoglobin $\mathrm{A}_{1 \mathrm{c}}\left(\mathrm{HbA}_{1 \mathrm{c}}\right) \geq 6.5 \%$ or the use of antidiabetic medication. We defined current smokers as individuals who had smoked any tobacco in the previous 12 months, and we included those who had quit within the past year $[8,9]$.

\section{Coronary angiography and coronary intervention}

The $\mathrm{PCl}$ was performed via a radial or brachial route. Prerequisites for transradial intervention were a sufficiently pulsating radial artery and the presence of an ulnar pulse with a palmar arch, as evidenced by the absence of digital ischaemia according to Allen's test. A transbrachial approach was attempted when Allen's test was negative and/or when the radial artery was already occluded or inaccessible due to an arterial spasm. Briefly, after puncture of the artery with a 22-G needle, a 0.025 -inch 220-cm guidewire (Radifocus ${ }^{\mathrm{TM}}$, Terumo, Japan) was advanced directly into the artery. With the distal tip of the guidewire positioned in the ascending aorta, the open dilator was inserted into the puncture site for artery dilation. After removing the open dilator, the sheathless guiding catheter, together with a central dilator (4-Fr) mounted inside, was inserted into the artery.

In the unplanned $\mathrm{PCl}$ group, a 0.025 -inch $220-\mathrm{cm}$ or a 0.035 -inch $200-\mathrm{cm}$ guidewire (Radifocus ${ }^{\mathrm{TM}}$, Terumo, Japan) was advanced through the 4-Fr introducer sheath after coronary angiography. With the distal tip of the guidewire positioned in the ascending aorta, the sheath was removed. Then, the hydrophilic-coated (Works ${ }^{\mathrm{TM}}$ ) or standard guiding catheter (Heartrail ${ }^{T M}$ ), together with a central dilator (4-Fr) mounted inside, was inserted into the artery. The sheathless guiding catheter was then advanced into the ascending aorta, the central dilator and the Radifocus ${ }^{T M}$ guidewire were removed, and unfractionated heparin $5000 \mathrm{IU}$ was administrated via the catheter. The sheathless guiding catheter was then manipulated into the target coronary artery. The $\mathrm{PCl}$ was performed using rapid exchange devices with either a 0.014-inch or a 0.010 -inch hydrophilic guidewire. The choice of stents was left to the discretion of the physician.

Although the hydrophilic-coated guiding catheter kit (Works ${ }^{\mathrm{TM}}$ ) contains a central dilator (4-Fr), this was not part of the standard guiding catheter kit. However, an optional central dilator (4-Fr) was available; therefore, V3$\mathrm{Fr} \mathrm{PCl}$ using a standard guiding catheter was performed (Figure 1).

\section{Catheter removal and haemostasis}

In all instances, the sheathless guiding catheter was removed immediately after successful $\mathrm{PCl}$ was confirmed by angiography. Haemostasis of the puncture site was achieved by application of a pressure bandage at either the radial arterial site (TR band ${ }^{T M}$, Terumo, Japan) or brachial arterial site (Tometa Kun ${ }^{\mathrm{TM}}$, Zeon Medical, Japan) (Figure 1). A pressure bandage over the punctured artery was usually applied for 2-4 h $[4,10]$. During compression, patients with radial/brachial puncture were not restricted to bed rest.

\section{Definitions}

Lesion success for virtual 3-Fr PCI was defined as angiographically confirmed successful revascularisation of the target lesion (i.e. a postprocedural residual stenosis of $<30 \%$ and a Thrombolysis In Myocardial Infarction (TIMI) 3 flow without exchange to a regular guiding catheter). Clinical success was defined as successful revascularisation without any ischaemic complications during in-hospital follow-up. An ischaemic event was defined as the occurrence of Q-wave or non-Q-wave myocardial infarction, a need for coronary artery bypass surgery, or a repeat $\mathrm{PCl}$ for acute coronary occlusion. A non-Q-wave myocardial infarction was defined as a rise in creatine phosphokinase-MB threefold greater than the upper limit of normal range. We also documented access site complications including bleeding, pseudoaneurysm, arteriovenous fistula, and infection [11]. A complication was considered to be major if it was associated with an extension of the hospital stay, haemoglobin loss of $\geq 2 \mathrm{mmol} / \mathrm{l}$, or the need for a blood transfusion or vascular repair. Radial artery occlusion was defined as the absence of a radial pulse confirmed by a negative reverse Allen's test, visible obstruction with two-dimensional ultrasound, or the absence of a positive Doppler signal, either alone or in combination. 


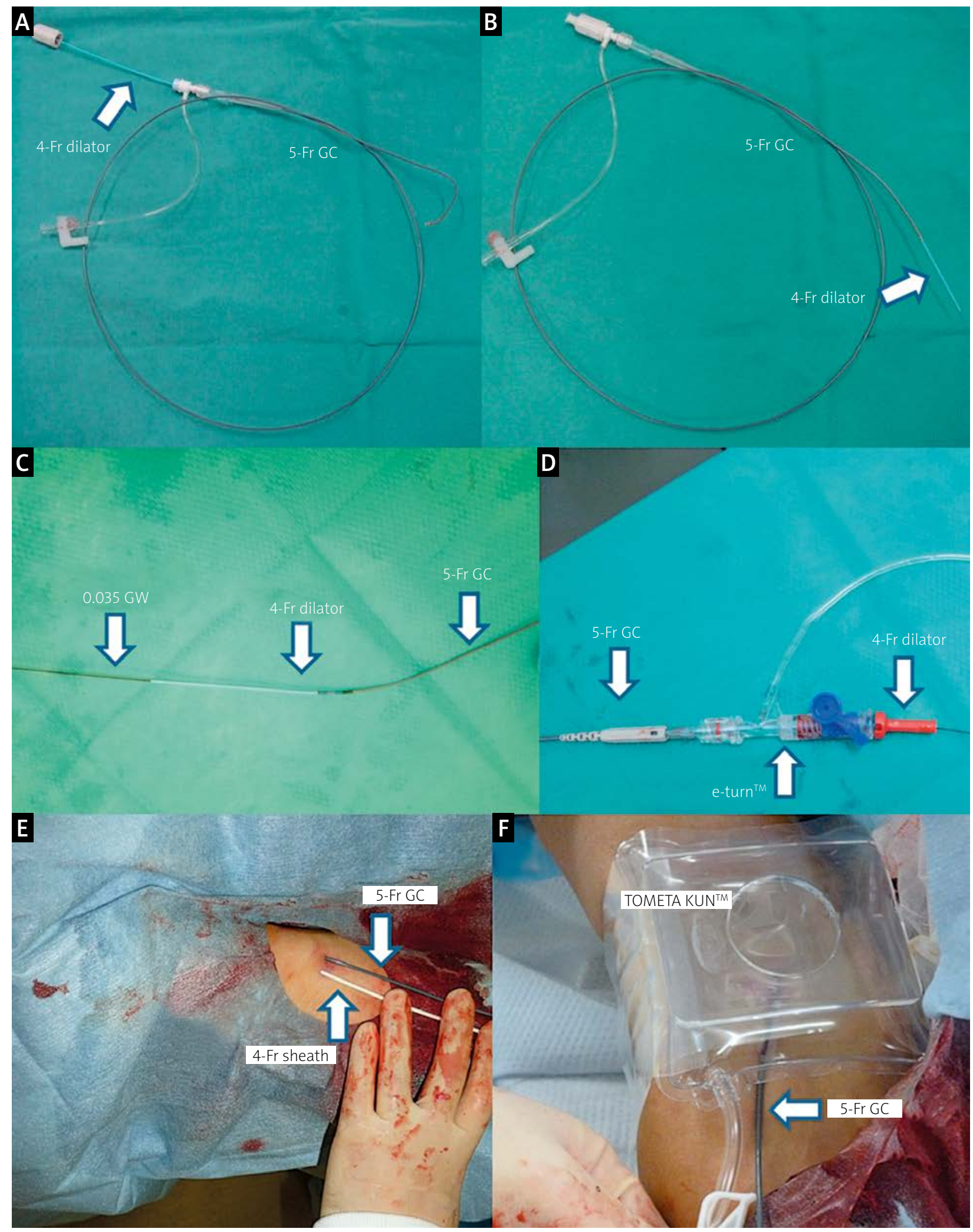

Figure 1. A colour photograph of the 4-Fr dilators and 5-Fr guiding catheters. A - A 5-Fr hydrophilic-coated guiding catheter and the additional 4-Fr dilator $\left(\right.$ Works $\left.^{T M}\right)$. B - The 4-Fr dilator is deeply inserted into the 5-Fr hydrophilic-coated guiding catheter (Works ${ }^{\mathrm{TM}}$ ). C, D - An optional 4-Fr dilator is deeply inserted into a 5-Fr standard guiding catheter (Heartrail ${ }^{\mathrm{TM}}$ ). E - A 5-Fr standard guiding catheter (Heartrail ${ }^{\mathrm{TM}}$ ) and a 4-Fr conventional sheath. $\mathbf{F}-\mathrm{A}$ haemostatic device (TOMETA KUN ${ }^{\mathrm{TM}}$ )

GC - guiding catheter, GW - guide wire 


\section{Statistical analysis}

The subjects in the analysis were divided into two groups according to the type of guiding catheters used (hydrophilic-coated or standard catheters). Differences in frequencies were analysed by the $\chi^{2}$ method. Continuous variables were compared between the two groups using a two-tailed paired $t$-test. Odds ratios (OR) and $95 \%$ confidence intervals $(\mathrm{Cl})$ for congestive heart failure were calculated using logistic regression analysis. Differences with $p<0.05$ were considered statistically significant for all analyses. Data were expressed as the mean \pm SD.

\section{Results}

\section{Patient and lesion characteristics}

Patient and lesion characteristics are depicted in Table I. Thirty-five patients were identified (63\% men, mean age $70 \pm 13$ years). A total of 35 lesions were treated, and they included 12 lesions (34\%) in the left anterior descending artery, 12 (34\%) in the circumflex arteries, and $11(31 \%)$ in the right coronary artery. The morphologies of these lesions consisted of 10 (29\%) type A, 10 (29\%) type B1, 10 (29\%) type B2, and 5 (14\%) type C, according to the AHA/ACC classification. No lesions had chronic total occlusion. The mean left ventricular ejection fraction was $64 \pm 10 \%$.

\section{Procedural characteristics}

Procedural characteristics are provided in Table II. The $\mathrm{PCl}$ was carried out via the radial route in 30 (86\%) patients and the brachial route in 5 (14\%). The shapes of the catheters used for left coronary artery interventions were Ikari left in 11 patients, Judkins left in 11, and $B L$ (backup left) in 2. For the right coronary artery interventions, the catheters used were Ikari left in 6 patients, Amplatz left in 2, Judkins right in 2, and Judkins left in 1.

In 2 cases, hydrophilic-coated guiding catheters were exchanged to standard guiding catheters because of difficulty in engaging the target coronary artery. Ultimately, standard guiding catheters were used in 20 patients (57\%), and hydrophilic-coated catheters were used in 15 patients (43\%).

Exchange from a virtual 3-Fr catheter to a conventional guiding catheter was not necessary in any patient. The $\mathrm{PCl}$ was successful in all patients (100\%). Balloon angioplasty only was performed in 3 patients (8.6\%), and stenting in 32 (91\%). No 5-Fr sheaths were used in this study.

Table I. Clinical and angiographic characteristics of patients

\begin{tabular}{|c|c|c|c|}
\hline Parameter & Hydrophilic-coated GCs $(n=15)$ & Standard GCs $(n=20)$ & Value of $p$ \\
\hline \multicolumn{4}{|l|}{ Patient characteristics: } \\
\hline Age, mean \pm SD [years] & $71 \pm 13$ & $70 \pm 13$ & 0.82 \\
\hline Male, $n(\%)$ & $10 / 15(66.7)$ & $12 / 20(60.0)$ & 0.69 \\
\hline $\mathrm{BMI}$, mean $\pm \mathrm{SD}\left[\mathrm{kg} / \mathrm{m}^{2}\right]$ & $22.7 \pm 2.4$ & $24.2 \pm 3.2$ & 0.13 \\
\hline Hypertension, $n(\%)$ & $12 / 15(80.0)$ & $17 / 20(85.0)$ & 0.99 \\
\hline Dyslipidaemia, $n$ (\%) & $12 / 15(80.0)$ & $16 / 20(80.0)$ & 0.99 \\
\hline Diabetes mellitus, $n(\%)$ & $10 / 15(66.7)$ & $10 / 20(50.0)$ & 0.30 \\
\hline Current smokers, $n(\%)$ & $5 / 15(33.3)$ & $6 / 20(30.0)$ & 0.99 \\
\hline Haemodialysis, $n(\%)$ & $0 / 15(0)$ & $0 / 20(0)$ & - \\
\hline Previous MI, n (\%) & $7 / 15(46.7)$ & $8 / 20(40.0)$ & 0.69 \\
\hline Previous CABG, $n(\%)$ & $0 / 15(0)$ & $1 / 20(5.3)$ & 0.99 \\
\hline LVEF, mean \pm SD & $62.7 \pm 11.4$ & $65.3 \pm 9.4$ & 0.47 \\
\hline Lesion site, $n(\%)$ : & & & 0.80 \\
\hline Left anterior descending & $6 / 15(40.0)$ & $6 / 20(30.0)$ & \\
\hline Circumflex & $5 / 15(33.3)$ & $7 / 20(35.0)$ & \\
\hline Right & $4 / 15(26.7)$ & $7 / 20(35.0)$ & \\
\hline Lesion AHA/ACC type, $n$ (\%): & & & 0.076 \\
\hline $\mathrm{A}, \mathrm{B} 1$ & $6 / 15(40.0)$ & $14 / 20(70.0)$ & \\
\hline $\mathrm{B} 2, \mathrm{C}$ & $9 / 15(60.0)$ & $6 / 20(30.0)$ & \\
\hline
\end{tabular}

GC - guiding catheter, BMI - body mass index, MI - myocardial infarction, CABG - coronary artery bypass graft, LVEF-left ventricular ejection fraction 
Table II. Procedural characteristics of patients

\begin{tabular}{|c|c|c|c|}
\hline Parameter & Hydrophilic-coated GCs $(n=15)$ & Standard GCs $(n=20)$ & Value of $p$ \\
\hline Ad-hoc coronary intervention, $n(\%)$ & $5 / 15(28.6)$ & $15 / 20(75.0)$ & 0.014 \\
\hline Access site, $n(\%)$ : & & & 0.68 \\
\hline Radial artery & $13 / 15(86.7)$ & $16 / 20(80.0)$ & \\
\hline Brachial artery & 2/15 (13.3) & $4 / 20(20.0)$ & \\
\hline Type of guiding catheters used, $n(\%)$ : & & & $<0.0001$ \\
\hline Judkins right & $1 / 15(6.7)$ & $1 / 20(5.0)$ & \\
\hline Judkins left & $12 / 15(80.0)$ & $0 / 20(0)$ & \\
\hline Amplatz & 2/15 (13.3) & $0 / 20(0)$ & \\
\hline Back-up & 0/15 (0) & $2 / 20(10.0)$ & \\
\hline Ikari left & 0/15 (0) & $17 / 20(85.0)$ & \\
\hline Use of 4-Fr guiding catheter, $n(\%)$ : & $1 / 15(6.7)$ & $1 / 20(5.0)$ & 0.99 \\
\hline Number of GWs used, mean \pm SD & $1.3 \pm 0.5$ & $1.3 \pm 0.9$ & 0.89 \\
\hline Number of BCs used, mean \pm SD & $1.0 \pm 0.4$ & $1.1 \pm 0.6$ & 0.78 \\
\hline \multicolumn{4}{|l|}{ Quantitative coronary angiography: } \\
\hline \multicolumn{4}{|l|}{ Pre-PCI, mean \pm SD: } \\
\hline Reference diameter [mm] & $2.58 \pm 0.50$ & $2.59 \pm 0.54$ & 0.97 \\
\hline Minimal lumen diameter [mm] & $0.58 \pm 0.14$ & $0.54 \pm 0.28$ & 0.63 \\
\hline Diameter stenosis (\%) & $76.7 \pm 7.1$ & $79.2 \pm 2.8$ & 0.42 \\
\hline \multicolumn{4}{|l|}{ Post-PCI, mean \pm SD: } \\
\hline Reference diameter [mm] & $2.78 \pm 0.38$ & $2.81 \pm 0.49$ & 0.84 \\
\hline Minimal lumen diameter [mm] & $2.25 \pm 0.27$ & $2.21 \pm 0.44$ & 0.68 \\
\hline Diameter stenosis (\%) & $22.2 \pm 6.9$ & $21.6 \pm 6.8$ & 0.80 \\
\hline Number of stents used, mean \pm SD [mm]: & $1.2 \pm 0.4$ & $1.3 \pm 0.9$ & 0.84 \\
\hline Mean stent diameter & $2.62 \pm 0.34$ & $2.64 \pm 0.43$ & 0.88 \\
\hline Stent length & $19 \pm 7$ & $26 \pm 19$ & 0.22 \\
\hline By deep vessel intubation technique, $n$ (\%) & $3 / 15(20.0)$ & $3 / 20(15.0)$ & 0.70 \\
\hline Lesion success, $n$ (\%) & $15 / 15(100)$ & $20 / 20(100)$ & \\
\hline Procedural success, $n(\%)$ : & $14 / 15(93.3)$ & $19 / 20(95.0)$ & 0.99 \\
\hline Procedural time, mean $\pm \mathrm{SD}[\mathrm{min}]$ & $50 \pm 26$ & $50 \pm 23$ & 0.95 \\
\hline Fluoroscopy time, mean \pm SD [min] & $13.02 \pm 8.49$ & $18.29 \pm 12.66$ & 0.27 \\
\hline Radiation dose, mean \pm SD [mGy] & $604.2 \pm 415.5$ & $1028.1 \pm 994.5$ & 0.23 \\
\hline Contrast dye volume, mean \pm SD [ml] & $55.2 \pm 19.8$ & $62.2 \pm 15.3$ & 0.25 \\
\hline
\end{tabular}

$G C$ - guiding catheter, $G W$ - guide wire, $B C$ - balloon catheter, $P C l$ - percutaneous coronary intervention

In 2 patients, the stents could not pass through because of previously implanted stents proximal to the site of the target lesions. After 4-Fr straight "child" guiding catheters were inserted into the 5-Fr sheathless "slender mother" guiding catheters (virtual 3-Fr PCI), they were deployed successfully at the target lesions.

There was no significant difference in procedural time, fluoroscopy time, radiation dose, or contrast dye 
volume between the two groups (Table II). Access site-related and procedural complications were not observed in this study.

\section{Discussion}

We report for the first time that virtual 3-Fr PCl via radial or brachial access using standard guiding catheters was as feasible and safe as 3-Fr PCl performed using hydrophilic-coated guiding catheters. There were no access site-related or procedural complications in this study. This procedure can be performed safely in patients with stable angina.

There were no differences in other patient characteristics between the group with hydrophilic-coated guiding catheters and the group with standard guiding catheters. Although a previous study using transradial catheterisation demonstrated that access site-related complications (radial artery occlusion and bleeding) were attenuated with a smaller sheath size, it was uncertain if downsizing by sheathless guiding catheters was associated with less entry-site complications [4]. Access site-related complications were not observed in this study using either the radial or brachial route, although a previous study showed that the vascular access bleeding complication rate for 5 - $\mathrm{Fr} \mathrm{PCl}$ without a sheath (virtual 3-Fr PCI) via femoral access was 5\% [12]. Our results are also consistent with a previous study that assessed the incidence of access site-related complications among radial, brachial, and femoral routes [2]. Although there was a possibility that the use of standard guiding catheters might exacerbate access site-related complications because of the lack of a hydrophilic coating, this study demonstrated that there was no difference in access site-related complications between the two groups. Based on the results of previous studies, a smaller arterial puncture might be expected to reduce access site-related complications regardless of the use of a conventional sheath or a hydrophilic-coated guiding catheter [4]. Thus, less invasive virtual 3-Fr PCI using a 5 -Fr guiding catheter is expected to be widely adopted by interventional cardiologists to attenuate access site-related complications.

There was no significant difference in the $\mathrm{PCl}$ procedural variables such as procedural time, fluoroscopy time, radiation dose, and contrast dye volume between the two groups, although unplanned PCl was performed more frequently in the group with standard guiding catheters than in the group with hydrophilic-coated guiding catheters. This was because at our institute unplanned virtual 3-Fr PCl was started after gaining experience by performing planned virtual 3-Fr procedures. Thus, unplanned virtual 3-Fr PCl can be frequently performed using standard guiding catheters. The $\mathrm{PCl}$ procedural time, fluoroscopy time, radiation dose, and contrast dye volume increased with unplanned $\mathrm{PCl}$ compared with scheduled $\mathrm{PCl}$, because $\mathrm{PCl}$ was performed following coronary angiography. On the other hand, the present study demonstrated that virtual 3-Fr PCl using standard guiding catheters was more invasive than virtual $3-\mathrm{Fr} \mathrm{PCl}$ using hydrophilic-coated guiding catheters due to the frequency of unplanned $\mathrm{PCl}$.

Although some techniques are available for virtual 3- $\mathrm{Fr} \mathrm{PCl}, 5-\mathrm{Fr}$ guiding catheters may limit the $\mathrm{PCl}$ devices and techniques that can be used [13-15]. If it is difficult to deploy a stent into the target lesion in virtual 3- $\mathrm{Fr} \mathrm{PCl}$, then deep seating of the guiding catheter, 2-wire technique, or 4-in-3 slender mother and child $\mathrm{PCl}$ technique may be useful to deliver the stent. In addition, combinations such as a 5-Fr Heartrail ${ }^{T M}$ guiding catheter (Terumo, Japan) and a 4-Fr KIWAMI STO1 Heartrail ${ }^{T M}$ guiding catheter (Terumo, Japan), and a 5-Fr Works ${ }^{T M}$ guiding catheter (MEDIKIT, Japan) and a 4-Fr i-Works ${ }^{\mathrm{TM}}$ guiding catheter (MEDIKIT, Japan) have been recommended to match the outer diameter of the "child" guiding catheter with the inner diameter of the "slender mother" guiding catheter. Without this type of matching, it may be difficult to insert a "child" guiding catheter from one manufacturer into a "slender mother" guiding catheter from another manufacturer.

In the present study, we excluded the patients with $\mathrm{AMI}$ or calcified coronary artery lesions. In treating these patients, aspiration catheters and debulking devices such as rotablators or cutting balloons are essential because they are performed via a 6-Fr or even larger system.

\section{Conclusions}

The present study indicated that virtual 3-Fr PCl using a standard guiding catheter was feasible and safe for the treatment of patients with stable angina, and associated with less access site-related complications than 3FR-PCI using a hydrophilic-coated guiding catheter.

\section{References}

1. Grüntzig A, Schneider HJ. The percutaneous dilatation of chronic coronary stenosis - experiments and morphology. Schweiz Med Wochenschr 1977; 107: 1588.

2. Kiemeneij F, Laarmann GJ, Odekerken D, et al. A randomized comparison of percutaneous transluminal coronary angioplasty by the radial, brachial and femoral approaches: the access study. J Am Coll Cardiol 1997; 29: 1269-75.

3. Ikari Y, Matsukage T, Yoshimachi F. Coronary intervention: less invasive strategy in $\mathrm{PCl}$. Cardiovasc Interv Ther 2012; 27: 84-92.

4. Honda T, Fujimoto K, Miyao Y, et al. Access site-related complications after transradial catheterization reduced with smaller sheath size and statins. Cardiovasc Interv Ther 2012; 27: 174-80.

5. Takeshita S, Saito S. Transradial coronary intervention using a novel 5-Fr sheathless guiding catheter. Catheter Cardiovasc Interv 2009; 74: 862-5.

6. Mizuno S, Takeshita S, Taketani Y, et al. Percutaneous coronary intervention using a virtual 3-Fr guiding catheter. Catheter Cardiovasc Interv 2010; 75: 983-8. 
7. Honda T, Fujimoto K, Miyao Y. Successful percutaneous coronary intervention using 4-in3 "slender mother and child" PCl technique. Postep Kardiol Inter 2013; 9: 286-90.

8. Honda $\mathrm{T}$, Kanazawa $\mathrm{H}$, Koga $\mathrm{H}$, et al. Heart rate on admission is an independent risk factor for poor cardiac function and in-hospital death after acute myocardial infarction. J Cardiol 2010; 56: 197-203.

9. Honda T, Fujimoto K, Miyao Y, et al. Current cigarette smoking is an independent risk factor for subacute stent thrombosis in acute myocardial infarction patients. J Cardiol 2014; 63: 358-64.

10. Sakatani T, Kawasaki T, Hadase M, et al. Novel application of the hemostatic device TOMETA KUNTM. Circ J 2003; 67: 895-7.

11. Thygesen K, Alpert JS, White HD; Joint ESC/ACCF/AHA/WHF Task Force for the Redefinition of Myocardial Infarction. Universal definition of myocardial infarction. Circulation 2007; 116: 2643-53.

12. Bayard YL, Jakob D, Meier B. All comers 5 French transfemoral percutaneous coronary intervention without sheath. Catheter Cardiovasc Interv 2011; 78: 47-51.

13. Saito S, Ikei H, Hosokawa G, et al. Influence of the ratio between radial artery inner diameter and sheath outer diameter on radial artery flow after transradial coronary intervention. Catheter Cardiovasc Interv 1999; 46: 173-8.

14. Yoshimachi F, Masutani M, Matsukage T, et al. Kissing balloon technique within a $5 \mathrm{Fr}$ guiding catheter using 0.010 inch guidewires and 0.010 inch guidewire-compatible balloons. J Invasive Cardiol 2007; 19: 519-24.

15. Yoshimachi F, Ikari F, Matsukage T, et al. A novel method of PercuSurge distal protection in a five French guiding catheter without an export aspiration catheter. J Invasive Cardiol 2008; 20: 168-72. 